\title{
The Impact of Manufacturer Coupon Use in the Statin Market
}

\author{
Jonas B. Daugherty, MS, RPh; Matthew L. Maciejewski, PhD; and Joel F. Farley, PhD
}

\begin{abstract}
BACKGROUND: Pharmaceutical manufacturer coupons are a rapidly growing promotional activity intended to encourage initiation and continuing use of brand-name medications, but little is known about impacts on medication adherence and expenditures.

OBJECTIVE: To understand which patients use manufacturer coupons and the impact of coupons on brand-name statin (atorvastatin and rosuvastatin) use and expenditures 1 year after initiation of statin therapy.

METHODS: Using commercially available claims data spanning 3 years and representing 340,350 patients, we compared demographics, statin use, and expenditures of patients initiating generic statins, brand-name statins without manufacturer coupons, and brand-name statins with manufacturer coupons. Differences in user groups were tested using chi-squared statistics and Wilcoxon-Mann-Whitney tests. Main outcome measures included statin fills, adherence, and expenditures, including patient out-of-pocket, payer, and total costs.
\end{abstract}

RESULTS: With the exception of population density, there were no significant demographic differences between new to therapy brand-name statin users filling prescriptions with and without coupons. New to therapy patients using generics were younger and lived in less populated areas compared with new to therapy brand-name statin noncoupon users. The number of statin fills in the 12 months following initiation was highest for coupon users, slightly lower for patients initiating generic statins, and lowest for noncoupon users (7.1 vs. 6.3 vs. $5.8 ; P<0.001)$, with corresponding medication adherence rates $(61.1 \%$ vs. $60.1 \%$ vs. $53.8 \% ; P<0.001)$. Coupon users had higher total statin prescription costs than generic initiators and noncoupon users ( $\$ 798$ vs. $\$ 92$ vs. $\$ 678 ; P<0.001$ ), and higher precoupon out-of-pocket costs ( $\$ 339$ vs. $\$ 53$ vs. $\$ 169 ; P<0.001)$. Health plan costs for statins excluding rebates were lower for coupon users than noncoupon users ( $\$ 460$ vs. $\$ 508 ; P<0.001$ ) but were much higher compared with generic statin initiators ( $\$ 460$ vs. $\$ 39 ; P<0.001$ ).

CONCLUSIONS: Brand-name statin initiators using coupons have higher adherence than patients initiating generic statins or brand-name statins without coupons. While the differences in adherence were statistically significant, they may not be clinically significant. Higher adherence among coupon users appears to occur at the expense of higher out-of-pocket and total statin expenditures.

\section{J Manag Care Pharm. 2013;19(9):765-72}

Copyright $\odot 2013$, Academy of Managed Care Pharmacy. All rights reserved.

\section{What is already known about this subject}

- Elevated serum cholesterol has long been identified as a major risk factor for the development of cardiovascular disease (CVD). The morbidity costs associated with CVD in the United States are staggering. In 2008, the annual cost of treating CVD in the United States was estimated to be $\$ 297.7$ billion.
- Medication adherence and persistence to statins is a significant challenge. A meta-analysis of statin adherence reports that the proportion of patients after 12 months of therapy with a medication possession ratio greater than $80 \%$ was only $51 \%$. The percentage of patients remaining on lipid-lowering therapy after 12 months is estimated to be only $65.5 \%$.

- Reduction in patient out-of-pocket costs has been shown to improve medication-taking behavior for statins.

- Manufacturer coupons have become a significant promotional tool for the pharmaceutical industry that is intended to reduce patient out-of-pocket costs.

- Very little is known about the impact of coupons on medication adherence and costs.

\section{What this study adds}

- Demographic characteristics of new statin patients who choose to use coupons do not differ in any practically significant way from noncoupon-using statin initiators.

- New to therapy brand-name statin patients using coupons had significantly more refills and significantly better medication adherence during the first year of therapy than noncoupon-using brand-name statin patients.

- There was no practical difference in medication adherence between new to therapy brand-name statin users who redeemed coupons and new to therapy generic statin users.

- Within plans, new to therapy brand-name statin patients using coupons tend to have higher prescription costs (excluding rebates) than noncoupon brand-name-using new statin patients and generic statin-using patients. It is unclear whether these slightly higher plan costs are driven by increased statin adherence or better medication adherence across all medications taken by coupon users.

$\mathrm{P}$ harmaceutical manufacturers have committed significant resources to promotional activities such as drug samples and copay discount coupons that reduce patient outof-pocket costs associated with the purchase of single-source branded medications. Pharmaceutical industry spending on samples was $\$ 15.9$ billion in 2004 , representing approximately $27.7 \%$ of overall promotional spending. ${ }^{1}$ As a result of this investment, $18.3 \%$ of patients taking a prescription medication received a drug sample between 1999 and $2005 .{ }^{2}$ Coupons are a smaller, but rapidly growing (260\% increase to $\$ 4$ billion in past 2 years), promotional activity that is estimated to generate a \$4-\$6 return on every dollar spent. ${ }^{3}$ 
However, coupon use has become contentious. Manufacturers argue that patients are familiar with coupons, coupons improve medication adherence by lowering patients' out-of-pocket costs, and coupons are a safer alternative to drug samples because drug dispensing requires a licensed pharmacist. ${ }^{4}$ Managed care organizations (MCOs) counter that coupons provide an incentive for patients to initiate and remain on brand-name medications when a suitable less costly generic medication is available, which interferes with the MCOs ability to ensure appropriate utilization and control medication expenditures. ${ }^{5-7}$

A recent editorial outlined the hypothetical impacts of coupons on patient and health plan costs for brand-name statins, ${ }^{4}$ but there is no empirical evidence to support or refute these competing claims. Given that manufacturer coupons likely reduce patient out-of-pocket expenses, a large body of literature supports the relationship between reductions in cost sharing and improvements in adherence. ${ }^{8-10}$ Of particular note, work by Pedan et al. (2007) found that adherence to statins was lower for patients with higher copayments. Their findings indicated that adherence decreased by $2.2 \%$ for every $\$ 10$ increase in copay $(P<0.001) .{ }^{11}$ However, there have been no empirical studies of the impact of coupons on adherence or health care costs.

To provide the first population-based evidence about the impact of coupons, we compared demographics, statin use, and expenditures of new to therapy (incident) users of generic statins, single-source brand-name statins without manufacturer coupon redemption, and single-source brand-name statins with manufacturer coupon redemption. We evaluated the impact of coupons on the statin drug class because of the important role that statins play in managing cardiovascular disease, ${ }^{12}$ the number of branded single-source statin manufacturers offering coupons for these agents, and the volume of statins prescribed in the United States each year. ${ }^{13}$ We examined incident statin users to understand the impact of coupons on statin initiation and improve comparability across cohorts in estimating the effect of coupons on adherence..$^{14}$

We also examined differences in demographic characteristics, statin fills, adherence, and drug costs across several plans with differing copayment structures for brand-name statins in an effort to inform formulary policy. These results provide the first empirical evidence clarifying manufacturer and MCO claims relative to the adherence and cost impacts of coupons in the statin market. Such information should enable more informed decisions with regard to formulary management of branded statin agents.

\section{Methods}

\section{Data}

The data used in this study are 2008-2010 retail prescription claims provided by Symphony Healthcare Solutions (SHS), identifying cash claims, primary and secondary insurance

\section{FIGURE 1 Percentage of Total Retail Claims} Captured by State $(2010)^{15}$

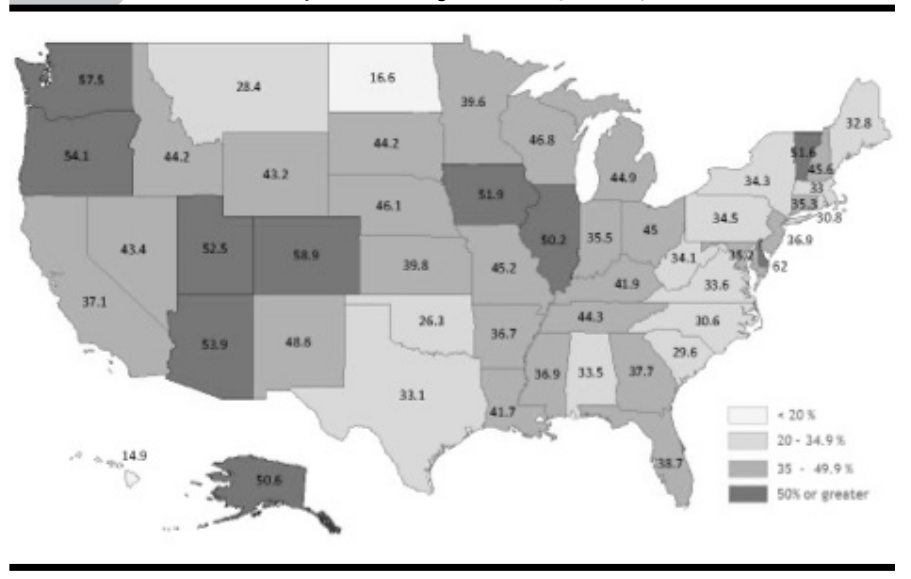

coverage, prescription expenditures, and coupon use. These unique data represent approximately $40 \%$ of prescriptions (brand and generic) used in the treatment of dyslipidemias filled by retail pharmacies in the United States and are geographically representative of the U.S. retail pharmacy market in terms of patient demographics and pharmacy ownership. These data are collected from retail pharmacies so they represent all payers, including commercial, Medicaid, Medicare, and cash. Mail-order pharmacy claims are not observable, but they do not bias these results because mail-order pharmacies generally do not accept coupons. The percentages of total retail claims captured by state as estimated by SHS $^{15}$ are displayed in Figure 1.

These data are uniquely suited for this analysis because they provide the ability to identify all sources of prescription payment, including primary payers, secondary payers, and cash payments by patients. Furthermore, these data facilitate longitudinal patient tracking upon changes in prescription coverage for patients remaining within the pharmacy cohort. Data related to income, education, and population density from 2010 census data were linked to these prescription claims to facilitate demographic comparisons between the cohorts.

\section{Study Design and Sample}

This study is a retrospective cohort analysis of incident users of select single-source/single-agent branded statin agents and generic statin therapy. Patients are uniquely identified as coupon users of atorvastatin or rosuvastatin, noncoupon users of the atorvastatin or rosuvastatin, or incident users of a generic statin (lovastatin, pravastatin, or simvastatin). During the observation period, atorvastatin and rosuvastatin had coupons in all geographies.

The initial data extract included more than 20.1 million patients who filled any prescription for a lipid-lowering agent, which was reduced to 2,082,444 patients aged 18-64 who 
received atorvastatin or rosuvastatin or a generic statin for the first time between January 1, 2009, and January 1, 2010. Of these 2.08 million incident statin users, patients were excluded if they were not commercially insured $(n=423,262)$ because coupons cannot be used by patients in federally funded programs (Medicaid or Medicare). A commercial population was also selected because use of coupons has been contentious in this population due to the potential impact of coupons on utilization and cost given the large numbers of insured patients. ${ }^{3,5,7}$ A patient is defined to have commercial coverage if more than $50 \%$ of their observed prescriptions during the observation period were reimbursed by a commercial payer. We excluded patients with a lapse in prescription activity of 3 or more continuous months during the 24-month period from January 1 , 2009, to December 31, 2010 ( $n=1,261,856)$, and if they lacked 1 year of prefill data to confirm initiation and 1 year of postfill data to track fills, adherence, and costs. ${ }^{16}$ We also excluded 56,976 patients who did not have complete data, resulting in a final analytic cohort of 340,350 patients. These patients were then defined as generic statin initiators, brand-name statin initiators with coupon redemption, or brand-name statin initiators without coupon redemption on the basis of the first observed statin filled in the study period. Patients were defined as a brand-name initiator if their first statin fill was for atorvastatin or rosuvastatin. Within this subgroup of brand-name initiators, patients were identified as coupon users if at least 1 coupon was used in a claim for atorvastatin or rosuvastatin during the 1-year observation period following the initiation of statin therapy. Otherwise, patients were defined as noncoupon users. A consort diagram is presented in Figure 2.

Coupons used in prescription fills were identified using unique payer identifiers corresponding to coupon vendors in the SHS claims data. A total of 12 coupon vendors were identified by the first author (Daugherty) from lists of coupon vendors provided by SHS and a nationally recognized consulting firm that provides syndicated reporting to the health care industries.

The analytic set contains data representing 340,350 patients within 1,327 unique commercial plans. From the original cohort, we identified a subsample of patients from 4 plans with at least 5,000 statin claims to examine whether the association between coupons, medication use, and expenditures varied across statin copayment levels. Of the 4 plans with 5,000 or more statin claims, the average copays ranged from $\$ 25$ to $\$ 38$ per 30-day fill of atorvastatin or rosuvastatin. Plans were selected subjectively to ensure a distribution in average copayments. The final subgroup of 4 plans contains 10,327 incident statin users.

\section{Outcomes}

We selected 2 statin utilization outcomes-count of statin fills and statin refill adherence- 1 year after initiation. To evaluate differences in medication adherence, we compared the medication possession ratio (MPR) for statin use among coupon-use

\section{FIGURE 2 Consort Diagram-Description of Filtering to Original Data to Create Patient Cohorts for Final Analysis}

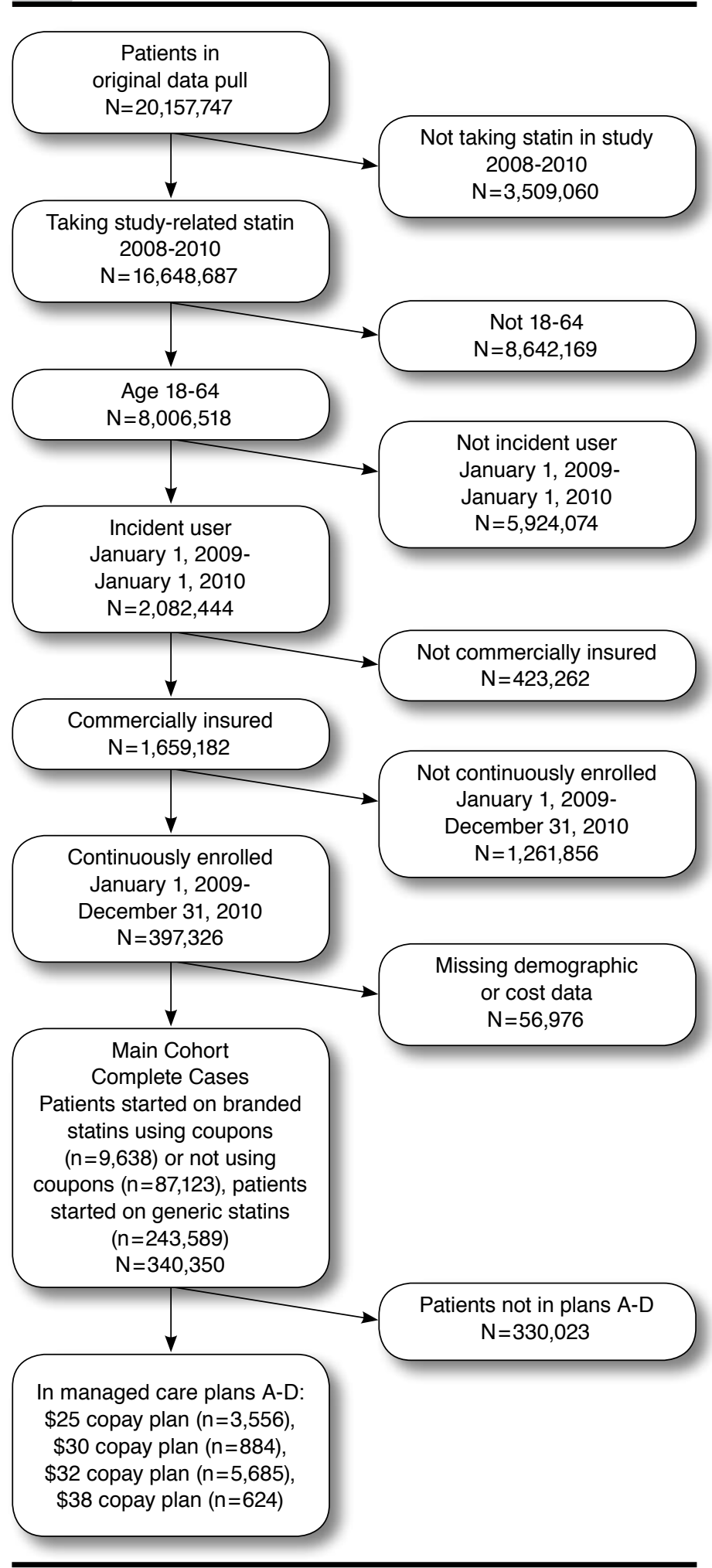




\begin{tabular}{|c|c|c|c|}
\hline & $\begin{array}{c}\text { Brand Non- } \\
\text { Coupon Users } \\
(\mathrm{n}=87,123) \\
\text { Mean (SE) }\end{array}$ & $\begin{array}{c}\text { Brand Coupon } \\
\text { Users } \\
(\mathbf{n}=9,638) \\
\text { Mean (SE) }\end{array}$ & $\begin{array}{c}\text { Generic } \\
\text { Users } \\
(\mathrm{n}=243,589) \\
\text { Mean (SE) }\end{array}$ \\
\hline \multicolumn{4}{|c|}{ Demographic Characteristics } \\
\hline Male (\%) & 47.7 & $47.4 \mathrm{~b}$ & $43.4^{\mathrm{d}}$ \\
\hline Age & $54.4(0.03)$ & $54.2(0.08)^{\mathrm{c}}$ & $54.0(0.01)^{\mathrm{c}}$ \\
\hline $\begin{array}{l}\text { Expected Rx-risk } \\
\text { score }\end{array}$ & $\$ 1,980(6)$ & $\$ 1,798(15)^{\mathrm{d}}$ & $\$ 1,846(3)^{\mathrm{d}}$ \\
\hline $\begin{array}{l}\text { Bachelor's degree in } \\
\text { ZIP code (\%)a }\end{array}$ & $25.5(0.03)$ & $24.5(0.09)^{\mathrm{d}}$ & $24.4(0.02)^{\mathrm{d}}$ \\
\hline $\begin{array}{l}\text { Median income in } \\
\text { ZIP code }\end{array}$ & $\$ 47,328(45)$ & $\$ 46,129(119)^{\mathrm{d}}$ & $\$ 45,596(23)^{d}$ \\
\hline $\begin{array}{l}\text { Population per square } \\
\text { mile in ZIP code }\end{array}$ & $2,987(33)$ & $1,491(52)^{d}$ & $1,692(12)^{\mathrm{d}}$ \\
\hline \multicolumn{4}{|c|}{ Medication Utilization in 12 Months Following Statin Initiation } \\
\hline $\begin{array}{l}\text { Count of fills for all } \\
\text { prescriptions }\end{array}$ & $40.3(0.10)$ & $39.0(0.25)$ & $40.3(0.06)^{c}$ \\
\hline $\begin{array}{l}\text { Total expenditures } \\
\text { for all prescriptions }\end{array}$ & $\$ 3,302(18)$ & $\$ 3,022(35)$ & $\$ 2,168(12)^{d}$ \\
\hline $\begin{array}{l}\text { Total nonstatin Rx } \\
\text { expenditures }\end{array}$ & $\$ 2,625(17)$ & $\$ 2,224(35)^{d}$ & $\$ 2,075(12)^{d}$ \\
\hline \multicolumn{4}{|l|}{ Statin use } \\
\hline Number of fills & $5.8(0.01)$ & $7.1(0.04)^{\mathrm{d}}$ & $6.3(0.01)^{d}$ \\
\hline Statin adherence (\%) & $53.8(0.11)$ & $61.1(0.30)^{\mathrm{d}}$ & $60.1(0.07)^{\mathrm{d}}$ \\
\hline $\begin{array}{l}\text { Percent of patients } \\
\text { MPR }>80 \%\end{array}$ & 30.4 & 36.7 & 38.4 \\
\hline \multicolumn{4}{|c|}{$\begin{array}{l}\text { aUsing } 2009 \text { data; ZIP code is aggregated to the first } 3 \text { digits. } \\
{ }^{2} P<0.05 . \\
{ }^{c} P<0.01 \text {. } \\
d P<0.001 \text {. } \\
\text { MPR= medication possession ratio; } R x=\text { prescription; } S E=\text { standard error. }\end{array}$} \\
\hline
\end{tabular}

groups. The MPR calculation used in this study was the total days of therapy available during the observation period divided by 365 (the length of the observation period). We dropped any days supply remaining after the l-year observation period. If the total of days supply dispensed exceeded 365, we truncated the MPR to $1.0 .^{17}$

We also selected 3 statin expenditure outcomes-out-ofpocket costs, plan costs, and total costs- 1 year after initiation. As the incentive to use a coupon may be related to the initial out-of-pocket prescription costs, we standardized the out-ofpocket costs to the cost prior to coupon use by adding the coupon discount to the final patient out-of-pocket cost noted on the claim. This facilitates comparison of copays among groups in an effort to identify patterns of coupon use that may be dependent upon the copay required by the primary insurer. To determine the gross cost of the medication to the plan, we subtracted the patient out-of-pocket costs from the total cost of the claim. Plan costs in this analysis do not take into consideration any rebates available from the manufacturers. All cost data are inflation adjusted to 2009 dollars.

\section{Explanatory Variables}

To examine demographic differences between the 3 cohorts, we examined gender, age, and comorbidity as measured by the Rx-Risk score. ${ }^{18}$ This score is a measure of comorbidity generated from the presence of prescription claims across 45 distinct pharmacologic classes shown to be predictive of prescription expenditures. Higher Rx-Risk scores generally represent higher levels of comorbidities. The Rx-Risk score has been shown to explain more variation in total medical expenditures than the Charlson Comorbidity Index. ${ }^{19,20}$ The Rx-Risk values represent the expected value of pharmacy costs. Population-weighted averages of median income, education (proportion earning a college degree), and population density (population per square mile) were estimated using 2009 census data at the 3-digit ZIP code level. This information is included to better understand the potential role of socioeconomic status on coupon use and is not meant to infer causal relationships.

\section{Statistical Analysis}

Continuous variables (age, Rx-Risk score, statin cost, and adherence) were compared among groups using the WilcoxonMann-Whitney test, while gender differences were examined using chi-squared tests. Due to the large sample size of the overall cohort, differences in the total sample are considered significant if $P<0.01$. Since the plan-level analysis is conducted on smaller samples, differences at the plan level are considered significant if $P<0.05$. All analyses were performed using SAS Enterprise Guide v4.2 (SAS Institute, Inc., Cary, North Carolina).

\section{Results}

\section{Characteristics, Medication Utilization, and Expenditures in the Overall Cohort}

The vast majority ( $n=243,589$ or $71.6 \%$ ) of the overall cohort initiated generic statins during the study period, $25.6 \%$ $(n=87,123)$ of the sample initiated statin therapy with atorvastatin or rosuvastatin and had no coupon use, and $2.8 \%$ $(n=9,638)$ initiated atorvastatin or rosuvastatin and used a coupon during the study period. Compared with noncoupon users who initiated statin therapy (Table 1), coupon users were slightly less often male $(47.4 \%$ vs. $47.7 \% ; P<0.01)$, slightly younger (54.2 vs. $54.4 ; P<0.01$ ), had lower expected comorbidity scores ( $\$ 1,798$ vs. $\$ 1,980 ; P<0.001)$, and lived in areas with modestly lower proportions of college graduates $(24.5 \%$ vs. $25.5 \% ; P<0.001)$ and lower population density $(1,491$ population/square mile vs. 2,987 population/square mile, $P<0.001$ ). Compared with generic statin initiators, coupon users who initiated atorvastatin or rosuvastatin therapy were more often male (47.4\% vs. $43.4 \%$; $P<0.01$ ), modestly older (54.2 vs. 54.0; $P<0.01$ ), had slightly lower comorbidity scores ( $\$ 1,798$ vs. $\$ 1,846 ; P<0.001$ ), and lived in areas with modestly higher 


\section{TABLE 2 Average 12-Month Prescription Count, Adherence, Rx Risk, Coupon} Redemption, and Coupon Value by Coupon Use by Managed Care Plan

\begin{tabular}{|c|c|c|c|c|c|c|c|c|c|c|c|c|}
\hline & \multicolumn{2}{|c|}{$\begin{array}{l}\text { Brand Initiating } \\
\text { Patient Sample }\end{array}$} & \multicolumn{2}{|c|}{$\begin{array}{c}\text { Plan A } \\
\text { (\$25 Average Copay) }\end{array}$} & \multicolumn{2}{|c|}{\begin{tabular}{|c|} 
Plan B \\
(\$30 Average Copay) \\
\end{tabular}} & \multicolumn{2}{|c|}{$\begin{array}{c}\text { Plan C } \\
\text { (\$32 Average Copay) } \\
\end{array}$} & \multicolumn{2}{|c|}{$\begin{array}{c}\text { Plan D } \\
\text { (\$38 Average Copay) } \\
\end{array}$} & \multicolumn{2}{|c|}{$\begin{array}{c}\text { Generic First } \\
\text { Patient Sample }\end{array}$} \\
\hline & n & Mean (SE) & $\mathrm{n}$ & Mean (SE) & $\mathrm{n}$ & Mean (SE) & n & Mean (SE) & $\mathrm{n}$ & Mean (SE) & $\mathrm{n}$ & Mean (SE) \\
\hline \multicolumn{13}{|c|}{ 12-Month Statin Count } \\
\hline No coupon use & 87,123 & $5.8(0.01)$ & 3,301 & $6.3(0.1)$ & 843 & $6.6(0.1)$ & 5,082 & $6.8(0.1)$ & 555 & $6.8(0.2)$ & 243,589 & $6.3(0.01)$ \\
\hline Coupon users & 9,638 & $7.1(0.04)^{c}$ & 255 & $7.0(0.2)^{b}$ & 41 & $8.1(0.5)^{\mathrm{a}}$ & 603 & $8.0(0.2)^{c}$ & 69 & $8.6(0.5)^{c}$ & & N/A \\
\hline \multicolumn{13}{|l|}{ Statin Adherence } \\
\hline No coupon use (\%) & & $53.8(0.1)$ & & $52.1(0.6)$ & & $55.2(1.1)$ & & $55.3(0.5)$ & & $57.5(1.4)$ & & $60.1(0.1)$ \\
\hline Coupon users (\%) & & $61.1(0.3)^{c}$ & & $57.8(2.0)^{\mathrm{a}}$ & & $66.6(4.2)^{\mathrm{a}}$ & & $64.6(1.2)^{c}$ & & $70.3(3.3)^{\mathrm{b}}$ & & N/A \\
\hline \multicolumn{13}{|l|}{ Rx Risk Score } \\
\hline No coupon use & & $\$ 1,980(6.2)$ & & $\$ 1,960(28.6)$ & & $\$ 1,931(71.2)$ & & $\$ 1,868(23.4)$ & & $\$ 1,785(66.5)$ & & $\$ 1,846(3.2)$ \\
\hline Coupon users & & $\$ 1,798(15.5)^{\mathrm{c}}$ & & $\$ 1,809$ (102.1) & & $\$ 1,702(187.4)$ & & $\$ 1,639(54.6)^{\mathrm{b}}$ & & $\$ 1,666(137.5)$ & & N/A \\
\hline $\begin{array}{l}\text { Average coupon } \\
\text { redemptions per } \\
\text { patient }\end{array}$ & 9,638 & $3.8(0.03)$ & 255 & $3.7(0.20)$ & 41 & $4.1(0.47)$ & 603 & $4.1(0.14)$ & 69 & $4.2(0.41)$ & & N/A \\
\hline $\begin{array}{l}\text { Average coupon } \\
\text { value }\end{array}$ & 26,344 & $\$ 16.17(0.09)$ & 868 & $\$ 14.55(0.46)$ & 148 & $\$ 15.19(0.67)$ & 2,188 & $\$ 17.01(0.29)$ & 264 & $\$ 21.44(0.89)$ & & N/A \\
\hline \multicolumn{13}{|l|}{$\begin{array}{l}a P<0.05 \\
b P<0.01 \\
c P<0.001\end{array}$} \\
\hline
\end{tabular}

proportions of college graduates $(24.5 \%$ vs. $24.4 \%$; $P<0.001)$ and lower population density (1,491 population/square mile vs. 1,692 population/square mile; $P<0.001)$. Those initiating generic statins had the lowest total and nonstatin-related prescription costs, followed by coupon users and noncoupon users (Table 1).

The number of statin fills in the 12 months following initiation was highest for coupon users, slightly lower for patients initiating generic statins, and lowest for noncoupon users (7.1 vs. 6.3 vs. $5.8 ; P<0.001$ ), with corresponding medication adherence rates (MPR $61.1 \%$ vs. $60.1 \%$ vs. $53.8 \% ; P<0.001$ ). However, the proportion of patients with $80 \%$ or greater adherence in the 12 months following initiation was highest for patients initiating generic statins, followed by coupon users and noncoupon users (38.4\% vs. $36.7 \%$ vs. $30.4 \%$; $P<0.001$ ) (Table 1). Coupon users redeemed an average of 3.8 coupons in the 12 months following initiation, with an average value of \$16.17 (Table 2).

Coupon users had total statin expenditures that were much higher than generic statin initiators ( $\$ 798$ vs. $\$ 92 ; P<0.0001)$, much higher out-of-pocket costs ( $\$ 339$ vs. $\$ 53 ; P<0.0001$ ), and much higher statin costs to the health plan (\$460 vs. $\$ 39$; $P<0.001$ ) (Figure 3). When comparing brand-name statin initiators, coupon users had somewhat higher total statin costs than noncoupon users ( $\$ 798$ vs. $\$ 678 ; P<0.0001$ ), much higher outof-pocket costs ( $\$ 339$ vs. $\$ 169 ; P<0.001)$, but lower health plan costs ( $\$ 460$ vs. $\$ 508 ; P<0.001)$.

\section{Characteristics, Medication Utilization, and Expenditures in the Managed Care Cohorts}

In an effort to identify impacts of coupon use within plans, we compared 4 commercial plans from 1 national MCO and 3 different pharmacy benefit managers with a range of average copays on a 30-day supply of the atorvastatin or rosuvastatin. Plans with the largest claim counts for 30-day supplies of atorvastatin or rosuvastatin with minimum average copay differences of $\$ 2$ were selected. The average copay for atorvastatin or rosuvastatin was \$25 in Plan A, \$30 in Plan B, \$32 in Plan C, and \$38 in Plan D (Table 2). As in the overall patient sample, coupon users in all 4 plans filled more prescriptions for statins than noncoupon users in the year following initiation: Plan A (7.0 vs. 6.3; $P<0.01)$, Plan B (8.1 vs. 6.6; $P<0.05)$, Plan $C$ ( 8.0 vs. 6.8; $P<0.001)$, and Plan D (8.6 vs. 6.8; $P<0.001$ ). Medication adherence to statins in the first year of initiation was significantly higher for coupon users across all plans: Plan A (54.5\% vs. $48.8 \%$; $P<0.05)$, Plan B (66.4\% vs. $50.0 \% ; P<0.01)$, Plan C (60.7\% vs. $50.7 \% ; P<0.001)$, and Plan D (67.1\% vs. 50.1; $P<0.001)$ (Table 2). Coupon redemptions ranged across plans from 3.7 to 4.2 , with the highest average coupon redemption rate (4.2 per patient) in the plan with the highest average copay (Plan D).

Consistent with higher numbers of statin fills and higher adherence, total first-year statin treatment costs and out-ofpocket costs for coupon users were higher than nonusers (Table 3). Health plan expenditures for statins were significantly higher for coupon users in the higher copay plans: Plan C (\$581 vs. $\$ 507 ; P<0.001)$ and Plan D ( $\$ 579$ vs. $\$ 473 ; P<0.01)$. 
The Impact of Manufacturer Coupon Use in the Statin Market

\section{TABLE 3 Statin Out-of-Pocket, Health Plan, and Total Costs by Coupon Use Overall and by Plan}

\begin{tabular}{|c|c|c|c|c|c|c|c|c|c|c|c|c|}
\hline & \multicolumn{2}{|c|}{$\begin{array}{c}\text { Brand First } \\
\text { Patient Sample }\end{array}$} & \multicolumn{2}{|c|}{$\begin{array}{c}\text { Plan A } \\
\text { (\$25 Average Copay) }\end{array}$} & \multicolumn{2}{|c|}{$\begin{array}{c}\text { Plan B } \\
\text { (\$30 Average Copay) }\end{array}$} & \multicolumn{2}{|c|}{$\begin{array}{c}\text { Plan C } \\
\text { (\$32 Average Copay) }\end{array}$} & \multicolumn{2}{|c|}{$\begin{array}{c}\text { Plan D } \\
\text { (\$38 Average Copay) }\end{array}$} & \multicolumn{2}{|c|}{$\begin{array}{c}\text { Generic First } \\
\text { Patient Sample }\end{array}$} \\
\hline & n & Mean (SE) & $\mathbf{n}$ & Mean (SE) & $\mathbf{n}$ & Mean (SE) & $\mathbf{n}$ & Mean (SE) & $\mathbf{n}$ & Mean (SE) & $\mathbf{n}$ & Mean (SE) \\
\hline \multicolumn{13}{|l|}{ 12-Month Rx Costs } \\
\hline \multicolumn{13}{|l|}{ Total Statin Costs } \\
\hline No coupon use & 87,123 & $\$ 678(1.7)$ & 3,301 & $\$ 706(8.4)$ & 843 & $\$ 705(16.0)$ & 5,082 & $\$ 716(6.7)$ & 555 & $\$ 723(21.0)$ & 243,589 & $\$ 92(0.3)$ \\
\hline Coupon users & 9,638 & $\$ 798(4.8)^{\mathrm{c}}$ & 255 & $\$ 798(30.6)^{b}$ & 41 & $\$ 883(59.1)^{\mathrm{a}}$ & 603 & $\$ 875(18.1)^{\mathrm{c}}$ & 69 & $\$ 975(57.4)^{\mathrm{c}}$ & & N/A \\
\hline \multicolumn{13}{|l|}{ Out-of-Pocket Costs } \\
\hline No coupon use & & $\$ 169(0.6)$ & & $\$ 152(2.4)$ & & $\$ 189(5.8)$ & & $\$ 209(2.5)$ & & $\$ 250(10.1)$ & & $\$ 53(0.1)$ \\
\hline Coupon users (precoupon) & & $\$ 339(3.1)^{c}$ & & $\$ 239(13.4)^{c}$ & & $\$ 333(30.5)^{c}$ & & $\$ 294(7.7)^{c}$ & & $\$ 395(27.0)^{c}$ & & N/A \\
\hline Coupon users (postcoupon) & & $\$ 194(1.7)^{\mathrm{c}}$ & & $\$ 169(6.6)$ & & $\$ 266(26.3)^{\mathrm{b}}$ & & $\$ 209(5.7)$ & & $\$ 293(22.9)^{b}$ & & N/A \\
\hline \multicolumn{13}{|l|}{ Net plan cost (before rebates) } \\
\hline No coupon use & & $\$ 508(1.4)$ & & $\$ 554(7.1)$ & & $\$ 516(13.0)$ & & $\$ 507(5.3)$ & & $\$ 473(16.3)$ & & $\$ 39(0.2)$ \\
\hline Coupon users & & $\$ 460(3.8)^{\mathrm{c}}$ & & $\$ 559(23.4)$ & & $\$ 550(48.6)$ & & $\$ 581(14.4) \mathrm{c}$ & & $\$ 579(40.6)^{\mathrm{b}}$ & & N/A \\
\hline \multicolumn{13}{|c|}{$\begin{array}{l}{ }^{a} P<0.05 \\
b_{P}<0.01 \\
{ }^{2} P<0.001 \\
\text { N/A = not applicable; } R x=\text { prescription; } S E=\text { standard error. }\end{array}$} \\
\hline
\end{tabular}

\section{FIGURE 3 Out-of-Pocket, Health Plan, and Total Statin Expenditures in 12 Months Following Statin Initiation}

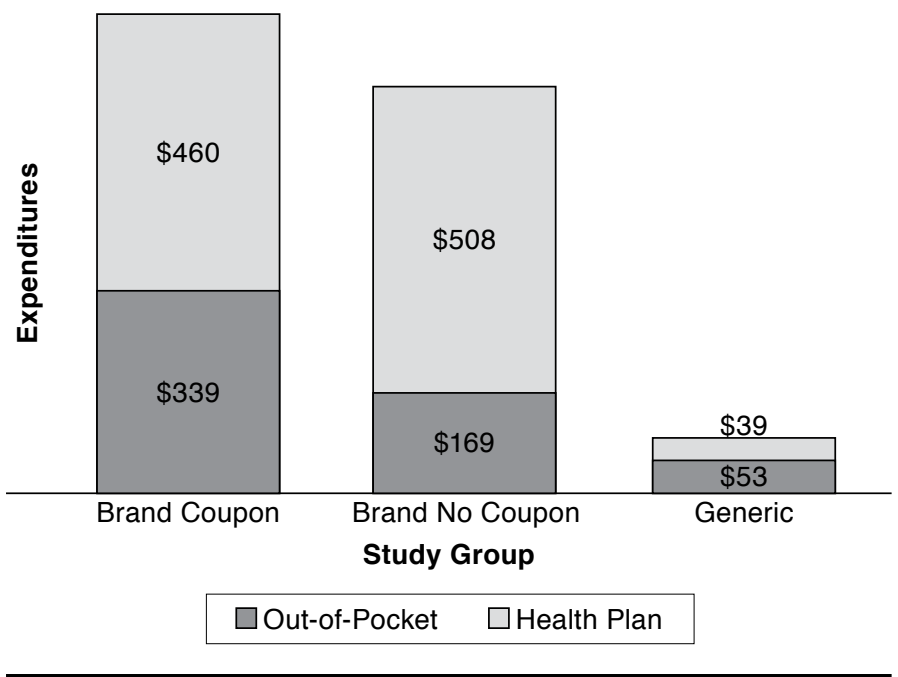

\section{Discussion}

There is an ongoing debate about the value of coupon programs among prescription manufacturers, MCOs, and patients. ${ }^{3-7}$ This study presents the most rigorous evidence to date regarding the impacts of coupons on medication adherence and costs based on a large cohort of incident users of rosuvastatin or atorvastatin. We find that brand-name statin initiators who used coupons had slightly higher adherence than patients initiating generic statins or brand-name statins without coupons.
The finding that noncoupon-using patients initiating brandname statins had lower adherence is not surprising as it is well established that high patient cost sharing is a significant barrier to medication adherence $e^{10,21,22}$ and that adherence to chronic medications improves when cost sharing is reduced. ${ }^{23,24}$

It is apparent from our study that coupon users experienced reduced out-of-pocket costs for branded statins. We find that reduced out-of-pocket costs were associated with improved adherence as demonstrated by coupon users filling 1.3 more prescriptions than noncoupon users in the year after initiation. These findings are consistent with literature examining the relationship between lower out-of-pocket cost and adherence..$^{8-11,23,24}$ In the plan subsample, coupon users in the plans with the highest statin copayment had 1.8 more fills than nonusers, while coupon users in the plans with the lowest statin copayment had 0.7 more fills than nonusers. This finding suggests that coupons are used more often by patients in plans with higher copayments.

We found evidence that greater adherence among coupon users came at the expense of higher out-of-pocket, health plan, and total statin expenditures. While coupon use appears to positively impact adherence to brand-name statins, overall pharmacy plan costs associated with coupon use are significant because the average annual plan costs for generic statin therapy was $\$ 39$ compared with $\$ 460$ for coupon users. This 12 -fold difference in statin cost provides a significant incentive for health plans to switch patients to a therapeutically equivalent generic when clinically appropriate. Therapeutic interchange programs for statins have been shown to be cost effective for payers. ${ }^{25,26}$ The impact of coupon use on total costs and outcomes remains an issue for further research. 
Research into the use of coupons for consumer package goods has shown that women ${ }^{27}$ and people with more education or higher incomes are more likely to use coupons. ${ }^{28}$ Prior research has shown that patients receiving prescription drug samples also tend to have higher income ${ }^{29}$ and are younger. ${ }^{30}$ We found that patients using coupons for brand-name statins were demographically distinct (less often male, slightly younger, and somewhat healthier) from patients receiving samples, which suggests that coupons may be reaching a different cohort of patients than samples. However, our expenditure results are consistent with prior work showing that patients receiving drug samples have higher prescription expenditures than their counterparts. ${ }^{30}$ Given the paucity of evidence about the characteristics of prescription coupon users, impacts on medication adherence and drug expenditures, and the rapid growth in coupon programs, future research should examine whether the results reported here remain consistent or vary by therapeutic class.

As evidenced from higher adherence among coupon users, coupon use may support adherence upon initiation of a statin in cases where the branded product is clinically appropriate. It is important to realize that coupon use is a self-selected activity requiring patients to remember to provide the coupon to the pharmacist when provided by the physician or to actively seek a coupon via the Internet and then provide the coupon to the pharmacy. In both cases, the patient displays a potentially higher level of engagement with their drug therapy. Patients with higher levels of engagement in their medical care, so-called healthy users, have been shown to have better medication adherence ${ }^{31,32}$ and better medical outcomes. ${ }^{32-34}$ It is unclear from these data if patients using coupons were those with higher levels of engagement or displayed higher levels of medication adherence in general. The relationship between coupon use, patient engagement, and prior medication adherence patterns should be a topic of further research.

\section{Limitations}

This study is subject to several limitations. As previously mentioned, we approximated patient characteristics of education, income, and population density by linking prescription claims to Census data because these data were not available in the prescription claims. These covariates aggregated to the 3-digit ZIP code level introduce significant potential for ecological fallacy and limit the statistical power compared with patientlevel covariates. The plan cost data should be interpreted with caution because manufacturer rebates have been omitted from plan costs. No attempts were made to model the impact of covariates on outcome measures. Lastly, the adherence measures used represent the average medication-taking behavior for all statins received by the patient. We did not identify switching behavior or changes in adherence that might have been associated with switches from brand to generic products.
This is significant because coupon-using patients who switch to a generic statin and maintain or improve their medication adherence with similar lipid-lowering effects represent a clearly cost-effective scenario for plans. It is unclear from this research if this is the case. Additional research is needed to resolve this question in an effort to further inform payer policy.

\section{Conclusions}

Brand-name statin initiators using coupons have slightly higher adherence than patients initiating generic statins or brand-name statins without coupons at the expense of higher out-of-pocket and total statin expenditures, which suggests that generics remain the most cost-effective pharmacotherapy for both patients and plans. Whether the impact of improved adherence associated with coupon use is associated with lower overall medical costs and improved outcomes remains an open question.

\section{Authors}

JONAS B. DAUGHERTY, MS, RPh, is a Doctoral Student, and JOEL F. FARLEY, PhD, is Associate Professor, University of North Carolina Eshelman School of Pharmacy, Chapel Hill. MATTHEW L. MACIEJEWSKI, PhD, is Professor, Duke University School of Medicine, Durham, North Carolina.

AUTHOR CORRESPONDENCE: Jonas B. Daugherty, MS, RPh, UNC Eshelman School of Pharmacy, 433 Pharmacy Ln., 2000 Kerr Hall, Campus Box 7573, Chapel Hill, NC 27599-7573.

Tel.: 919.824.6765; Fax: 919.966.8486;

E-mail: jbdaughe@email.unc.edu.

\section{DISCLOSURES}

Daugherty is currently employed in Global Health Outcomes at GlaxoSmithKline and holds stock and stock options at GlaxoSmithKline. Maciejewski and Farley have received consultation funds from Takeda Pharmaceuticals, Novartis, and the Surgical Review Corporation. Maciejewski is supported by a VA HSR\&D Research Career Scientist Award (RCS-10-391); he owns stock in Amgen due to his spouse's employment. None of the authors have any affiliation with companies, products, or services mentioned in this article.

Data used in this analysis were provided by Source Healthcare Analytics, a division of Symphony Health Solutions. This work was undertaken as a feasibility assessment in advance of the lead author's doctoral dissertation. There was no sponsor, so authors had the entire responsibility for the design, conduct, collection, management, analysis, and interpretation of the data. There were no external influences on preparation, review, or approval of the manuscript. Study concept and design were primarily the work of Daugherty, with assistance from Farley and input from Maciejewski. Daugherty was responsible for data collection; data interpretation was primarily the work of Daugherty, with assistance from Maciejewski and Farley. The manuscript was written by Daugherty, with assistance from Farley; its revision was the work of all authors. 


\section{REFERENCES}

1. Gagnon MA, Lexchin J. The cost of pushing pills: a new estimate of pharmaceutical promotion expenditures in the United States. PLOS Med. 2008;5(1):29.

2. MacDougall C, Udkow T, Guglielmo BJ, Vittinghoff E, Martin J. National estimates and predictors of prescription medication sample use in the United States, 1999-2005. J Am Pharm Assoc. 2010;50(6):677-85.

3. Visante. How copay coupons could raise prescription drug costs by $\$ 32$ billion over the next decade [white paper]. Pharmaceut Care Manage Assoc. November 2011.

4. Grande D. The cost of drug coupons. JAMA. 2012;307(22):2375-76.

5. Joffe-Walt C. Drug coupons hide true costs from consumers. 2009. Available at: http://www.npr.org/templates/story/story.php?storyId= 113969968. Accessed October 20, 2011.

6. Kalmans W. Copay programs-drug coupons improve healthcare quality and lower costs. Wharton Magazine. 2011. Available at: http://texasenterprise. org/print/604. Accessed January 19, 2012.

7. Rockoff JD. Drug makers criticized for co-pay subsidies Wall Street Journal. July 20 2009. Available at: http://online.wsj.com/article/ SB124804603437163631.html. Accessed February 7, 2011.

8. Gibson TB, Ozminkowski RJ, Goetzel RZ. The effects of prescription drug cost sharing: a review of the evidence. Am J Manag Care. 2005;11(11):730-40.

9. Goldman DP. Prescription drug cost sharing: associations with medication and medical utilization and spending and health. JAMA. 2007;298(1):61-69.

10. Eaddy MT, Cook CL, O'Day K, Burch S, Cantrell CR. How patient cost-sharing trends affect adherence and outcomes: a literature review. PT. 2012;37(1):45-55

11. Pedan A, Varatesh LT, Schneeweiss S. Analysis of factors associated with statin adherence in a hierarchical model considering physician, pharmacy, patient, and prescription characteristics. J Manag Care Pharm. 2007;13(6):487-95. Available at: http://www.amcp.org/WorkArea/ DownloadAsset. aspx?id=7639.

12. Ross SD, Allen IE, Connelly JE, et al. Clinical outcomes in statin treatment trials: a meta-analysis. Arch Intern Med. 1999;159(15):1793-802.

13. Top Therapeutic Classes by Prescriptions. Norwalk, CT: IMS Health; 2011. Available at: http://www.imshealth.com/deployedfiles/imshealth/ Global/Content/StaticFile/Top_Line_Data/2010_Top_Therapeutic_Classes_ by_RX.pdf. Accessed December 29, 2011

14. Kessler RC, Cantrell CR, Berglund P, Sokol MC. The effects of copayments on medication adherence during the first two years of prescription drug treatment. J Occup Environ Med. 2007;49(6):597-609.

15. Percentage of Retail Claims Captured by State (2010). Phoenix, AZ: Symphony Healthcare Analytics; 2012.

16. Abbas S. Estimation of disease incidence in claims data dependent on the length of follow-up: a methodological approach. Health Serv Res. 2012:47(2):746-55

17. Hess LM, Raebel MA, Conner DA, Malone DC. Measurement of adherence in pharmacy administrative databases: a proposal for standard definitions and preferred measures. Ann Pharmacother. 2006;40(7):1280-88.
18. Fishman PA, Goodman MJ, Hornbrook MC, Meenan RT, Bachman DJ, O'Keeffe Rosetti MC. Risk adjustment using automated ambulatory pharmacy data: the RxRisk model. Med Care. 2003;41(1):84-99.

19. Farley JF, Harley CR, Devine JW. A comparison of comorbidity measurements to predict healthcare expenditures. Am J Manag Care. 2006;12(2):110-19.

20. Maciejewski ML, Liu C-F, Derleth A, McDonell M, Anderson S, Fihn SD. The performance of administrative and self-reported measures for risk adjustment of veterans affairs expenditures. Health Serv Res. 2005;40(3):887-904.

21. Ellis JJ, Erickson SR, Stevenson JG, Bernstein SJ, Stiles RA, Fendrick M. Suboptimal statin adherence and discontinuation in primary and secondary prevention populations. J Gen Intern Med. 2004;19(6):638-45.

22. Balkrishnan R. Predictors of medication adherence in the elderly. Clin Ther. 1998;20(4):764-71.

23. Maciejewski ML, Farley JF, Parker J, Wansink D. Copayment reductions generate greater medication adherence in targeted patients. Health Aff. 2010;29(11):2002-08

24. Sedjo RL, Cox ER. Lowering copayments: impact of simvastatin patent expiration on patient adherence. Am J Manag Care. 2008;14(12):813-18.

25. Grace KA, Swiecki J, Hyatt R, et al. Implementation of a therapeuticinterchange clinic for HMG-CoA reductase inhibitors. Am J Health-Syst Pharm. 2002;59(11):1077-82

26. Meissner B, Dixon M, Shingole JA, Reeder CE, Belazi D, Senevirante V. Drug and medical cost effects of a drug formulary change with therapeutic interchange for statin drugs in a multistate managed Medicaid organization. J Manag Care Pharm. 2006;12(4):331-40. Available at: http://www.amcp.org/ WorkArea/DownloadAsset.aspx?id=7370.

27. Harmon SK, Hill CJ. Gender and coupon use. J Prod Brand Manage. 2003;12(3):166

28. Bawa K, Shoemaker RW. The coupon-prone consumer: some findings based on purchase behavior across product classes. J Mark. 1987;51(4):99-110.

29. Cutrona SL, Woolhandler S, Lasser KE, Bor DH, McCormick D, Himmelstein DU. Characteristics of recipients of free prescription drug samples: a nationally representative analysis. Am J Public Health (1971). 2008;98(2):284-89

30. Alexander GC, Zhang J, Basu A. Characteristics of patients receiving pharmaceutical samples and association between sample receipt and out-ofpocket prescription costs. Med Care. 2008;46(4):394-402.

31. Mosen DM, Schmittdiel J, Hibbard J, Sobel D, Remmers C, Bellows J. Is patient activation associated with outcomes of care for adults with chronic conditions? J Ambul Care Manage. 2007;30(1):21-29.

32. Parchman ML, Zeber JE, Palmer RF. Participatory decision making, patient activation, medication adherence, and intermediate clinical outcomes in type 2 diabetes: a STARNet study. Ann Fam Med. 2010;8(5):410-17.

33. Wong ST, Peterson S, Black C. Patient activation in primary healthcare: a comparison between healthier individuals and those with a chronic illness. Med Care. 2011;49(5):469-79.

34. Remmers C, Hibbard J, Mosen DM, Wagenfield M, Hoye RE, Jones C. Is patient activation associated with future health outcomes and healthcare utilization among patients with diabetes? J Ambul Care Manage. 2009;32(4):320-27. 